\title{
MATERNITY CARE SERVICES; ACCESSIBILITY AMONG RURAL WOMEN IN DISTRICT FAISALABAD
}

1. M.Phil., Lecturer, Government College University, Layyah Campus

2. Post Doctorate,

Associate Professor,

Government College University, Faisalabad

3. M.Phil., Lecturer, Government College University, Faisalabad

4. Director Medical Sciences, Government College University, Faisalabad

Correspondence Address:

Article received on: 14/03/2016

Accepted for publication: 02/05/2016

Received after proof reading: 26/05/2016

\section{Sadaf Faiz¹, Dr. Zahira Batool'2, Sana Ejaz ${ }^{3}$, Prof. Dr. Abid Rashid ${ }^{4}$}

ABSTRACT... Introduction: Maternal health care refers to high quality health care provided to a pregnant woman during pregnancy, delivery and postnatal period. The maternal mortality ratio is quite high in the rural areas of Pakistan. Rural society is highly associated with its traditions and cultural values. There are some cultural and social barriers for women. They are being considered negligible part of the population and are facing a number of hardships in availing health facilities. Objective: The aim of the study was to find out the socioeconomic, cultural and demographic factors affecting the access of rural women to maternity care services. Study Design: A cross-sectional study was conducted in the rural areas of District Faisalabad. Quantitative research method was used to get meaningful, detailed information. Material and Methods: A sample of 205 pregnant women aged 18-38 was taken, purposively to explore the research objectives through pre-designed interviewing schedule with open and closed ended questions. Results: Univariate and bivariate analysis reveal the factors associated with the utilization of maternity care services such as education of the respondents and their husbands, family type, household income, age at marriage, attitudes towards health care facilities were found to be associated with the utilization of maternity care service. Conclusion: The study reveals that a number of reproductive problems occurred among pregnant women in the rural areas of Pakistan due to the limited health facilities, socio-demographic and cultural barricades which restricted them to utilize maternity care services

Key words: Maternity care, household, socio-cultural, marriage, postpartum, social barriers

Article Citation: Faiz S, Batool Z, Ejaz S, Rashid A. Maternity care services; accessibility among rural women in district Faisalabad. Professional Med J 2016;23(6):721-726. DOI: $10.17957 / T P M J / 16.3346$

\section{INTRODUCTION}

Maternal health care refers to high quality health care provided to a pregnant woman during pregnancy, delivery and postnatal period. Maternity care includes the antenatal and postnatal care of the mother and the newborn. Antenatal care is given to pregnant women for their secure pregnancy and healthy baby. ${ }^{1}$ In low income countries a primary cause of death in childbearing age is pregnancy related complications. ${ }^{2}$ The ratio of maternal mortality in rural Zambia is over 500 deaths per 100000 live births due to the lack of knowledge about maternal health care and transportation problems. $^{3}$ Five major complications cause maternal mortality are hemorrhage, infection, complication of unsafe abortion, hypertension, and obstructed labor. ${ }^{4}$ Another important factor is adolescent pregnancies which accelerate the risk for both mother and newborn. Many studies show that adolescents have lack of experience and they are less mature to deal with pregnancy complications. Moreover, greater risk of poor health, premature delivery, adverse effects on infants, and the high morbidity rate is associated with adolescent pregnancies. ${ }^{5}$ Due to the low level of education and lack of awareness childbearing practice may be life threatening experience for them. Approximately 20,000 adolescent girls give birth every day and this phenomenon can be greatly reduced by decreasing adolescent pregnancy. Annually, more than five hundred thousand women die worldwide from obstetric complications from which $99 \%$ deaths occur in those countries where the fertility rate is high but lack of health facilities. ${ }^{6}$ In developing countries, approximately $35 \%$ of women do not receive antenatal care, $50 \%$ gives birth at home without 
the supervision of any health care professional and $70 \%$ not able to get postpartum care services. ${ }^{7}$ Maternal mortality rates are alarmingly high in Pakistan due to the pregnancy related complications, leading to 30,000 deaths every year. This problem is quite severe in the rural areas of Pakistan. ${ }^{8}$ For a woman, pregnancy is a critical period because it poses health risks to her child and herself, but in developing countries poor communities use less health care. ${ }^{9}$ Problems with availability, accessibility and affordability increase the inequality in delivering care among poor and rich class. ${ }^{10}$ Improvements in professional delivery care may abolish this difference among the rural poor. Obstetric complications can be treated in fully equipped health institutions with the help of proper medications and trained staff. But in many developing countries where social status is low, increased trust in traditional care, lack of awareness and ethnicity resulted in less access to modern health services, people favor to give birth at home rather than to go to hospital. ${ }^{11}$

But now there has been a considerable improvement with the passage of time. Over the past 11 years antenatal care service utilization ratio increased from $43 \%$ (2001) to $61 \%$ (2006$07)$ and to $73 \%(2012-13)$ according to the recent survey of (PHDS, 2012-13). The health care provider comprises of doctor, lady health worker and traditional birth attendant (midwives) can play vital role in decreasing maternal mortality rate with the help of appropriate training and the availability of modern equipments. Women in Pakistan have a high rate (56\%) of postpartum depression. This condition may persist until one year of postpartum. Different predictors, such as demographic, reproductive health, social and mental health related factors have been implicated for common mental health problems during the postnatal period in studied area. ${ }^{12}$ Health care seeking behavior is affected by social, economic, cultural, organizational, geographical and environmental factors. ${ }^{13}$ Arrogant behavior of health care providers discourages rural community to avail the health care services. ${ }^{14}$ In most rural areas the health services infrastructure is not developed and high rate of home based births done by traditional midwives usually unhygienic, which causes maternal and neonatal mortality. ${ }^{15}$ Pakistani society is highly patriarchal and gender discrimination is particularly acute. Rural women tend to rely on traditional remedies while males receive hospital treatment which showing the social devaluation of women and their attitude of self-neglect due to lower social status as compared to males. ${ }^{16}$ Significant gender differentials and culturally defined gender roles in the social and economic sphere also prevent women to utilize maternity care services. ${ }^{17}$ Poor roads and lack of transportation in the rural areas hindered women to avail maternity care services. On health care utilization, great advancement has been made in South Asia, but in Pakistan still inadequate studies on this problem. There is a need to conduct more studies on maternity care services utilization in the rural areas of Pakistan. This study aims to recognize the awareness regarding maternity care services, prenatal and postnatal health care seeking behavior, and obstacles facing by the women of rural areas in order to utilize these services. To make health care strategies most effective there is a need to study maternal perceptions and experiences of the rural women regarding health care practices.

\section{OBJECTIVES}

1) To study the socio-economic characteristics of respondents.

2) To investigate the awareness level of rural women about maternity care services.

3) To find out the socioeconomic and cultural problems faced by the rural women to avail these facilities.

4) To suggest some policy measures to make possible women's access to maternity care services.

\section{METHODOLOGY}

Quantitative research method was used. It helps to inquire about determinants or relationships in a sample that can be assumed and assessed to be true of the population from which the sample is drawn. The universe of the present study was district Faisalabad. It is highly populated with a population about $5,429,547$. The population of Faisalabad represents 7.4 percent of Punjab and 4.1 percent population of Pakistan. ${ }^{18}$ Sampling is 
the process of selecting a subset of individuals from a large group of individuals, which represents the characteristics of the whole population. To observe the effect of socioeconomic and cultural variables on maternity care services utilization cross-sectional study was conducted. For selection of the respondents' multistage random sampling technique was used. At first stage, one town was selected out of 8 towns randomly. At second stage, one union council was selected by employing simple random sampling. At third stage, two villages, Chak Nullah Wala and Chak Bilal Nager were selected randomly. At fourth stage respondents were selected by using purposive sampling. Total 205 pregnant women selected from the both villages as sample size for the study.

\section{RESULTS AND DISCUSSIONS}

\begin{tabular}{|l|c|c|}
\hline \multicolumn{1}{|c|}{ Response } & Frequency & Percentage \\
\hline Yes & 58 & 28.3 \\
\hline No & 147 & 71.7 \\
\hline Total & 205 & 100.0 \\
\hline
\end{tabular}

Table-I. Awareness level of rural women regarding postpartum care services

Above table demonstrates that the majority of respondents $(71.7 \%)$ had no awareness regarding postpartum care and only (28.3\%) respondents were aware regarding postpartum care services. That is really terrible situation, need is to create awareness among rural women about the importance of postpartum care services to decrease the chance of complications which may occur after delivery.

\begin{tabular}{|l|c|c|}
\hline \multicolumn{1}{|c|}{ Socio-cultural constraints } & Frequency & $\%$ \\
\hline Due to conservative thoughts & 74 & 36.1 \\
\hline Due to Cultural values & 69 & 33.7 \\
\hline Against family traditions & 20 & 9.8 \\
\hline TBAs treatment is much better & 14 & 6.8 \\
\hline Allowed & 28 & 13.7 \\
\hline Total & 205 & 100.0 \\
\hline
\end{tabular}

Table-II. Socio-cultural constraints to avail postpartum care services for rural women
Above table indicates that $(36.1 \%)$ respondents were not allowed due to conservative thoughts followed by (33.7\%) respondents were not allowed due to cultural values and (9.8\%) of the respondents said they were not allowed due to use health care services because these are against our family traditions while (6.8\%) said they are preferring Traditional Birth Attendant's (TBAs) treatment. Some respondents said they are living in a joint family system and their husbands are afraid of what will be the reaction of their family.

\begin{tabular}{|l|c|c|}
\hline \multicolumn{1}{|c|}{$\begin{array}{c}\text { General Reasons for not } \\
\text { using health care services }\end{array}$} & Frequency & $\%$ \\
\hline Due to low level of education & 56 & 27.3 \\
\hline Lack of resources & 49 & 23.9 \\
\hline Lack of time \& money & 80 & 39.0 \\
\hline $\begin{array}{l}\text { Non cooperative behavior of } \\
\text { in-laws }\end{array}$ & 77 & 37.6 \\
\hline Traveling issues & 77 & 37.6 \\
\hline $\begin{array}{l}\text { Long wait at hospital \& non- } \\
\text { cooperative behavior of staff }\end{array}$ & 65 & 31.7 \\
\hline $\begin{array}{l}\text { Table-III. General reasons for not using antenatal and } \\
\text { postnatal care services among rural women }\end{array}$ \\
\hline
\end{tabular}

Table above shows that the frequency distribution, (39.0\%) respondents described lack of time and money prevent women from using maternity care services. Household income positively affects the use of maternity care in Pakistan. ${ }^{19}$ In a joint family system in-laws have a strong influence on the decision of utilizing maternity care services. (37.6\%) respondents could not avail these services due to non-cooperative behavior of inlaws. Mumtaz et al. $2011^{20}$ revealed that one of the respondents was a victim of domestic violence and her in-laws believe she did not deserve maternity care. 77 respondents told women cannot utilize these services due to transportation problems and travelling issues. The economic disparity between rural-urban areas is an important reason for less utilization of maternity care services. Women from rural areas cannot avail health care services in case of emergency due to long distance and poor transportation. ${ }^{21}$ (31.7\%) respondents said women feel hesitate to attain maternity care due to the long wait at 
hospitals and non-cooperative behavior of staff. (23.9\%) respondents indicate that due to lack of resources women cannot access the maternity care. Lack of social resources also contributes in less utilization of health care. ${ }^{22}$ (27.3\%) respondents disclosed that due to low level of education, women are not fully aware about the use of antenatal and postnatal care services.

\begin{tabular}{|l|c|c|c|}
\hline \multirow{2}{*}{ Family type } & \multicolumn{2}{|c|}{ Receiving antenatal care } & Total \\
\cline { 2 - 3 } & Yes & No & \\
\hline Illiterate & $8(3.9 \%)$ & $41(20.0 \%)$ & $49(23.9 \%)$ \\
\hline Primary & $11(5.4 \%)$ & $30(14.6 \%)$ & $41(20.0 \%)$ \\
\hline Middle & $13(6.3 \%)$ & $20(9.8 \%)$ & $33(16.1 \%)$ \\
\hline Matric & $18(8.8 \%)$ & $25(12.2 \%)$ & $43(21.0 \%)$ \\
\hline Intermediate & $25(12.2 \%)$ & $14(6.8 \%)$ & $39(19.0 \%)$ \\
\hline Total & $75(36.6 \%)$ & $130(63.4 \%)$ & $205100.0 \%)$ \\
\hline
\end{tabular}

Table-IV. Lower the education of the women lowers the level of awareness regarding maternal health care Chi-square $=23.7$ d. $f=4$ Significance $(P)=.000 * \star$ Gamma $=-.472$

Table above presents the association between education of the women and the awareness regarding maternal health care. The chi-square value (23.7) shows a highly-significant association $(P=.000)$. There is a significant relationship between education of the women and lowers the level of awareness regarding maternal health care. The gamma value shows a strong positive relationship between the variables. It means highly. So the hypothesis "Lower the education of the women lowers the awareness regarding maternal health care" is accepted.

Table above presents the association education of the respondent's husband and betters the access towards maternity care. The chi-square value (62.7) shows a highly-significant association $(P=$ .000). There is a significant relationship between education of the respondent's husband and better access towards maternity care. The gamma value shows a strong positive relationship between the variables. It means highly. So the hypothesis "Higher the education of the respondent's husband betters the access towards maternity care" is accepted.

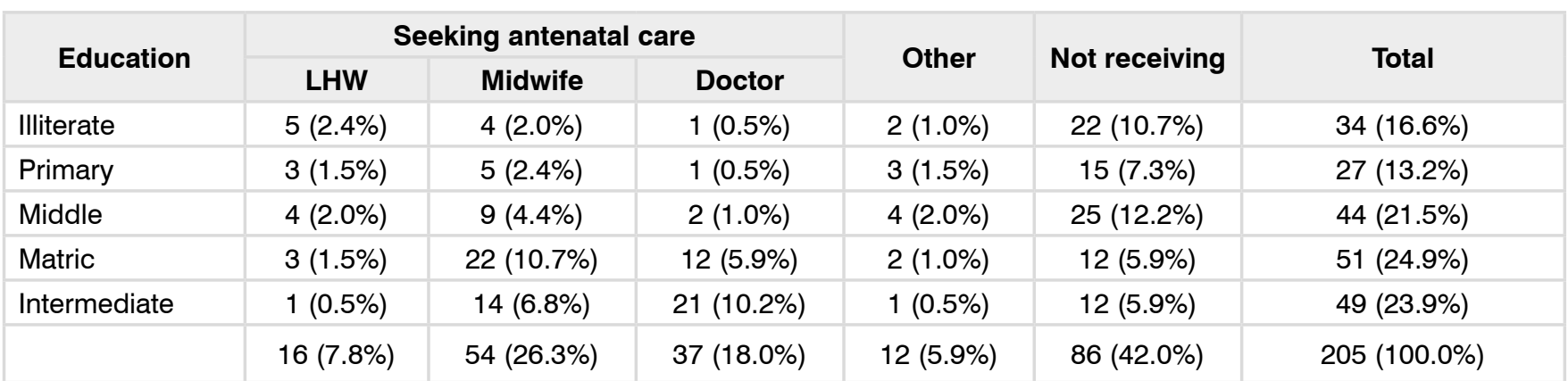

Table-V. Higher the education of the respondent's husband, higher the access towards maternity care. Chi-square $=62.7 \quad$ d.f. $=16$ Significance $(P)=.000 * \star \quad$ Gamma $=-.23$

\begin{tabular}{|c|c|c|c|c|c|c|}
\hline \multirow{2}{*}{ Income } & \multicolumn{3}{|c|}{ From whom seeking antenatal care } & \multirow{2}{*}{ Other } & \multirow{2}{*}{ Not receiving } & \multirow{2}{*}{ Total } \\
\hline & LHW & Midwife & Doctor & & & \\
\hline$<10000$ & $2(1.0 \%)$ & 20 (9.8\%) & $2(1.0 \%)$ & $5(2.4 \%)$ & 62 (30.2\%) & $91(44.4 \%)$ \\
\hline $20001-30000$ & $5(2.4 \%)$ & 14 (6.8\%) & $14(6.8 \%)$ & $2(1.0 \%)$ & $4(2.0 \%)$ & 39 (19.0\%) \\
\hline $\begin{array}{l}30001 \text { and } \\
\text { above }\end{array}$ & $3(1.5 \%)$ & $2(1.0 \%)$ & $15(7.3 \%)$ & $1(0.5 \%)$ & $0(0.0 \%)$ & $21(10.2 \%)$ \\
\hline
\end{tabular}


Table above presents the association between the monthly household income of the respondent and from whom they seeking antenatal care. The chi-square value (99.5) shows a highlysignificant association $(P=.000)$. The income of the household positively effects the seeking of antenatal care. Respondents with high household income consult with doctor. The gamma value shows a strong positive relationship between the variables. So the hypothesis "Higher income of the household positively effects the seeking of antenatal care" is accepted.

\section{CONCLUSION}

The study reveals that a number of reproductive problems occurred among pregnant women in the rural areas of Pakistan due to the limited health facilities, socio-demographic and cultural barricades which restricted them to utilize maternity care services. Significantly educational level of husband and the respondents, awareness of women regarding maternity care and household income enhance the use of maternity care. Lack of awareness regarding maternal health also prevents the access of rural woman toward maternity care services. Other factors such as financial problems distance from health care center, poor infrastructure, transportation, traditional beliefs, lack of women's autonomy, long wait at hospital and non-cooperative behavior of the staff hindered rural women from utilizing maternity care services. Following are the major suggestions by the researcher based on the analysis findings

Copyright(C) 02 May, 2016.

\section{REFERENCES}

1. Abosse, Z., Woldie, M., \& Oloo, S. Factors Influencing Antenatal Care Service Utilization in Hadiya Zone. Ethiop J Health Sci; 2010;20(2), 75-82.

2. Patton, G.C., Viner, R.M., Linh, L.C., Ameratunga, S., Fatusi, A.O., et al. Mapping a global agenda for adolescent health. Journal of Adolescent Health; 2010;47(5): 427-432.

3. Ensor, T., Green, C., Quigley, P., Badru,R.A., Kaluba .D \& Kureya.T., (2013). Mobilizing communities to improve maternal health: results of an intervention in rural Zambia. Bulletin of the World Health Organization 2014; 92:51-59.
4. Ayele, Z.D., Belayihun, B., Teji, K., \& Ayana, A.D. (2014). Factors Affecting Utilization of Maternal Health Care Services in Kombolcha District, Eastern Hararghe Zone, Oromia Regional State, Eastern Ethiopia. International Scholarly Research Notices; Volume 2014, Article ID 917058.

5. Raj A, Saggurti N, Balaiah D, Silverman JG. Prevalence of child marriage and its effect on fertility and fertility-control outcomes of young women in India: a cross-sectional, observational study. The Lancet; 2009;373(9678), 1883-89.

6. Desai, J. The cost of emergency obstetric care: concepts and issues. Int J Gynecol Obstet; 2003;81, 74- 82.

7. "Coverage of Maternity Care: A Listing of Available Information, Fourth Edition". World Health Organization, Geneva, 1997.

8. Midhet, F., \& Becker, S. Impact of community-based interventions on maternal and neonatal health indicators: Results from a community randomized trial in rural Baluchistan, Pakistan. Reproductive Health, 2010;7(1).

9. Gwatkin, D.R., Rutstein, S., Johnson, K., Pande, R.P., Wagstaff, A. (2000). Socio-economic differences in health, nutrition, and populationin India, HNP/ Poverty Thematic Group, World Bank, May 2000. www.world bank.or/hnp.

10. Naseem, K., Khurshid, S., Khan, SF., Moeen, A., Farooq, MU. Sheikh, S., Bajwa, S., Tariq, N., \& Yawar, A. Health related quality of life in pregnant women: A comparison between urban and rural populations. Journal of Pakistan Medical Association; 2011;61(3), 308-312.

11. Dhakal, S., Chapman, G.N., Simkhada, P.P., Teijlingen, E.R.V., Stephens, J., \& Raja, A.E. Utilization of Postnatal Care among Rural Women in Nepal. Department of Public Health University of Aberdeen, Aberdeen, AB25 2ZD, UK 2006.

12. Rahman, A., \& Creed, F. "Outcome of prenatal depression and risk factors associated with persistence in the first postnatal year: Prospective study from Rawalpindi, Pakistan." Journal of Affective Disorders; 2007;100(1-3), 115-121.

13. MacKian, S. A review of health seeking behaviour: problems and prospects. Health Systems Development Programme, University of Manchester 2003.

14. Atuyambe.L, Mirembe.F, Johansson.A, Kirumira.E.K, Faxelid.E, (2005), Experiences of pregnant adolescents-voices from Wakiso district, Uganda: 
African Health Sciences 2005; 5(4): 304-309.

15. Shaikh, B.T., Hatcher, J. "Health seeking behavior and health service utilization in Pakistan: Challenging the policy makers." Journal of Public Health; 2005;27(1), 49-54.

16. Anjum, Q. Girl Child Today - Mother of a Nation Tomorrow Department of Community Health Sciences, Ziauddin Medical University, Karachi. Inj Prev. September 2005; 6(3): 219-222.

17. Durrant, V.L., Sathar, Z.A. Greater investments in children through women's empowerment: the key to demographic change on Pakistan? Paper presented at the annual meeting of the population association of America, Los Angeles, USA 2000.

18. Census Report of Pakistan. Pakistan Census Organization, Government of Pakistan 1998.
19. Sara, N., and Khan, EA. (2011). Socioeconomic Determinants of Prenatal-care Utilization in Pakistan. http://saicon2011.ciitlahore.edu.pk/Economics/1182. pdf accessed on 21/5/2014.

20. Mumtaz, Z., Salway, S., Shanner, L., Bhatti, A., \& Laing, L. Maternal deaths in Pakistan: intersection of gender, caste, and social exclusion. BMC International Health and Human Rights; 2011;11(2).

21. Ali, M., Hotta, M., Kuroiwa, C., and Ushijima, H. Emergency obstetric care in Pakistan: Potential for reduced maternal mortality through improved basic EmOC facilities, services, and access. International Journal of Gynecology and Obstetrics 2005; 91, 105112.

22. Bakeera, S.K., Wamala, S. P., Galea, S., Peterson, S., \& Pariyo, G. W. Community perceptions and factors influencing utilization of health services in Uganda. International journal for equity in health 2009; 8, 25.

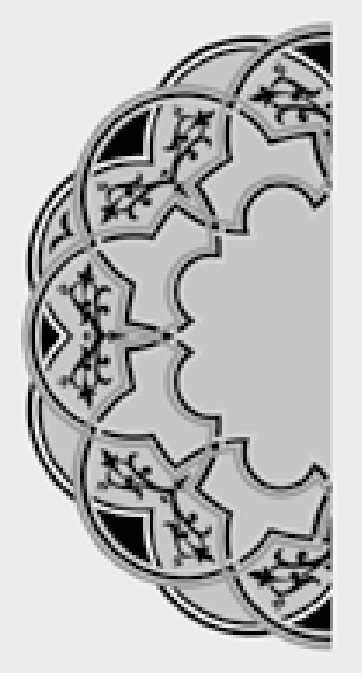

\author{
"Stop wishing for it \\ and \\ start working for it."
}

\title{
AUTHORSHIP AND CONTRIBUTION DECLARATION
}

\begin{tabular}{|c|c|c|c|}
\hline Sr. \# & Author-s Full Name & Contribution to the paper & Author $=\mathbf{s}$ Signature \\
\hline 1 & Sadaf Faiz & Write up & \\
\hline 2 & Dr. Zahira Batool & Analysis of data & \\
\hline 3 & Sana Ejaz & Review of literature & \\
\hline 4 & Prof. Dr. Abid Rashid & Proof reading & \\
\hline
\end{tabular}

